\title{
The Foreign TA Problem from an Acquisition-Theoretic Point of View
}

\author{
Josh Ard
}

\begin{abstract}
The purpose of this paper is to relate research on second language acquisition and research on the language problems of foreign teaching assistants and their remediation. On the one hand, SLA findings could improve the specific instructional programs required for foreign teaching assistants. On the other hand, second language acquisition research has not addressed specific data of this type. I argue that several vogue models of second language acquisition cannot explain the specific data without amendments. In particular, the psychological construct of attention is an important factor in determining whether or not the specific language use expected of college teachers will be attained by foreign students.
\end{abstract}

\section{Introduction}

An especially interesting problem of second langugage acquisition involves foreign teaching assistants in American universities. In American universities some graduate students are hired as teaching assistants. Some of these positions simply involve grading, but others require face-to-face interactions with undergraduates either in conducting actual class sessions or in holding tutorial or office hour meetings. In these environments, teaching assistants are expected to talk and to respond like competent college teachers. This requires some knowledge of the discipline and of the educational system, but it also requires some facility in a particular variety of English discourse. Some of these teaching assistants are non-native speakers of English. There has been increasing concern with (a) how well these non-native speakers in general master the language skills required of their position, (b) how to determine which of these foreign students do not have sufficient language abilities, and (c) how to aid those foreign students who are lacking. Several important results have been achieved in these areas (Bailey, Pialorski, \& Zukowski/Faust, 1984; Rounds, 1987).

What has not yet received much attention is the relationship between second language acquisition theory and the particularities of how foreign teaching assistants acquire or fail to acquire the language abilities necessary for success in their jobs. This relationship should not be ignored. On the one hand, it is to be hoped that second language acquisition theory can contribute toward alleviating the problems. On the other hand, the problems are significant for second language acquisition theory. If second language acquisition theory is a general theory, it should cover this specific type of acquisition (which has inherent importance for American universities). If it does not cover this type of acquisition, then the theory is valid only for certain types of acquisition and it is important to determine which specific types of acquisition it does and does not cover.

Address for correspondence: The Program in Linguistics, 1076 Friese, The University of Michigan, Amn Arbor, MI 48109, USA. 
It may seem unfair to test claims made about second language acquisition against the experience of foreign teaching assistants, since no theoretical claims directly address these questions. Hence, the theories have not explicitly said anything that could be falsified. Nonetheless, a general theory should be applicable here, so the implications can be tested.

I argue that theories of second language acquisition are not adequate to account for this specific type of second language acquisition. The theories have postulated that certain factors are necessary and/or sufficient for successful acquisition. In other words, success or failure should correlate with the presence or absence of certain variables. Not every researcher postulates the same variables. In this paper, I will consider three of the most commonly proposed variables: comprehensible input, negotiated input, and comprehensible output. Krashen (1980) argues that ceteris paribus if second language acquirers receive comprehensible input containing some particular language phenomenon which is just beyond their competence, they will acquire that phenomenon. Varonis and Gass (1985) claim that more may be required: acquisition will occur if the acquirer is able to negotiate through language interaction to receive comprehensible input containing the phenomenon just beyond their competence. Swain (1985) suggests that in addition to receiving comprehensible input, acquirers may need to output the target forms in conditions of meaning interaction.

If these variables are really the effective causes of second language acquisition, then their presence or absence should correlate with successful and unsuccessful acquisition of the language abilities necessary for foreign teaching assistants. That is, those foreign teaching assistants who have acquired what they need should have had these conditions met, while those who have failed should not have had these conditions met.

This is not the case. Recall that successful teaching assistants talk and respond like college teachers. By and large they acquire (or fail to acquire) these abilities before they are hired. That is, the bulk of the acquisition occurs when they are simply graduate students (if not before). There is no evidence that the amount of comprehensible input received alone determines which graduate students will demonstrate mastery of the discourse skills required of teaching assistants. After all, where this input would be heard is in the classroom (and academic office), to which all graduate students have equal access. Moreover, in their role as graduate students they would have little or no opportunity to practice talking like a teacher (i.e., comprehensible output). Finally, there is no evidence the graduate students that learned well how to talk and respond like teachers were those that engaged in interactions that motivated their teachers to talk in a special way (i.e., negotiated input). In fact, foreign students generally initiate few interactions in the clasroom. Hence, none of these variables by themselves can account for the acquisition or lack thereof.

\section{Wider Contexts of the Problem}

Before we consider alternative hypotheses that could account for the data, it is proper to consider the problem in a wider context. There are at least major differences between general studies of second language acquisition and the 
particularities of how foreign graduate students learn how to talk and respond like American college teachers. First, this problem concerns the acquisition of a special purpose language use, not a general quotidian one; second, this problem concerns the acquisition of discursive competence, not simply the acquisition of phonology, morphology, and syntax. Third, the language required is discursively asymmetric. Let us examine these in more detail.

It needs to be recognized that language abilities of foreign teaching assistants do not correlate exactly with overall language proficiency, rather, as discussed by Bailey (1984), there is a threshold level for success. That is, there is a minimum level of language proficiency necessary for success as a teaching assistant. Although this threshold level is necessary, it is not sufficient. Above the threshold level, it is impossible to predict success on the basis of overall language proficiency. Students just above the threshold may prove better at using classroom and academic office discourse than those well above the threshold. Foreign graduate students who can talk and respond like American college teachers are not necessarily the best at American English, globally.

Second, the problem of talking and responding like an American college teacher is obviously a matter of discursive competence. That is, the issue at hand concerns the ability to produce and react to discourse. This involves two possibly separable types of knowledge: (a) knowledge of the genre rules of classrooms and academic offices, (see Bakhtin 1986 for a thorough discussion of speech genres) and (b) the knowledge of how to apply forms allowed by the genre in actual face-to-face interaction. There is actually very little research in second language acquisition that directly addresses how discursive competence develops. ${ }^{1}$ This does not mean that discourse has been ignored, rather, we could say that discourse has formed the background for much second language research but has rarely been foregrounded. It has formed the context for acquisitional questions, and yet the intricacies of changes in discursive abilities have not received the same attention.

Third, even less attention has been paid to the acquisition of asymmetric discourse; by this I am referring to the acquisition of properties of discourse types that might be addressed to second language learners that they themselves would not normally be called upon to use in the same dyadic communication. The situation here is very different from the acquisition of syntax, phonology, and lexis. Although native speakers will be more competent in these three areas, in principle, learners could be expected to use the same grammatical structures, canonical pronunciations, and words native speakers do in interacting with them. The situation of asymmetric discourse is also different from properties of ordinary conversations. Non-native speakers could potentially use the same devices and structures native speakers do, for example, rules of turn-taking, making small talk, using indirect speech acts, etc. Teacher-student discourse and several other types of discourse, such as doctor - patient, counselor - client, etc., are

\footnotetext{
"As an example of the unusual nature of research questions into the acquisition of discuraive competence in a second language, take the citations in the most recent volumes of Language and Lamguage Baha vior Abstracts Under the citations in the index for discourse and oral langunge, none of the cited articles directly adtress the question of developments of discursive competence.
} 
asymmetric. The differences in power motivate different expectations about what types of discourse are appropriate for the interlocutors. Patients and doctors, students and teachers, etc. do not talk in the same way.

\section{Attention as the Key to the Problem}

None of the three variables discussed above adequately account for why some foreign teaching assistants perform well enough in language-based tasks while others do not. Hence, there is a need for another explanation. In this paper, I propose that this problem cannot be explained unless attentional factors (i.e., as used in psychology) are emphasized. The major reason that foreign teaching assistants have difficulties in mastering the language of the classroom and academic office is that they do not normally attend with adequate precision to the properties of classroom and academic office. This explanation points to a potential remedy: students need to be drawn into attending to the relevant language factors.

Before the case for attention can be developed, it is necessary to review research about attention. First, we will consider general research about the relevance of attention in learning. Second, we will consider the place of attention in second language acquisition research. Third, we will consider reasons why foreign teaching assistants have not attended closely enough to the relevant properties of classroom and academic office language use.

\section{Attention in General Learning Theories}

Attention is emphasized as an important factor in predicting success on learning tasks in contemporary learning research in both America and the Soviet Union. In America, the mathemagenic approach (Rothkopf, 1970) stresses which "instructional activities and sequences . . . 'give birth to learning" " (Jonassen, 1985, p. 10). In other words this approach claims that teachers and materials can inherently help students to act in manners that aid learning. The generative approach (Wittrock, 1974a, 1974b, 1978) stresses individual and learner-generated strategies (Jonassen, 1985, p.13). It claims that the learners themselves determine their acts to a much greater degree than teachers or instructional material. Although there are definite differences between these two approaches, what is of relevance, is an area of agreement - both emphasize the importance of attention. Both approaches emphasize that learners must attend to phenomena before they can be learned. The difference lies primarily in whether the learner determines what to attend to.

Soviet research on learning has likewise taken attention as a basic component. Leontiev (1981) summarizes Gal'perin's (1959) notion of orientation, which is viewed as the basis for an act. In general, orientation refers to the analysis of a target act a learner will be expected to perform. The notion is much more akin to the mathemagenic approach discussed above, as much emphasis is placed on finding a way to present material in a manner that fosters orientation. For example, one of the tasks of instruction is to aid the learner in finding the correct 
analysis of the target act. One facet of this is to make the learner aware of exactly what must be done.

\section{Attention in Second Language Learning}

Attention has also been discussed explicitly with regard to second language learning/acquisition. In general terms, it is important to consider whether the leamer attends to the ambient speech or ignores it (Larsen-Freeman 1983). More particularly, several investigators have considered factors that tend to increase attention. For example, Hakuta (1976) claims that learners are more likely to attend to morpho-syntactic forms that are overtly marked. Furthermore, some investigators have emhasized the role of attention in particular language skills. For example, Nagle and Sanders (1986) maintain that attention plays an essential role in the process of comprehending spoken language.

The studies cited in the above paragraph demonstrate that attention is important in second language learning, but do not precisely locate it in a model of second language acquisition. That has been accomplished in a model recently developed by Gass (forthcoming). She suggests a multi-stage relationship linking ambient speech to learners' output:

ambient speech $>$ apperceived input $>$ comprehended input $>$ intake $>$ integration $>$ output

In her model, the primary role of attention is in determining apperceived input. Crudely, apperceived input consists of input that is noticed and is related to something that has been previously learned. If something is noticed, clearly it is attended to. Similarly, learners are more likely to attend to things that related in some way to their previous knowledges and experiences.

\section{Predispositions for Attention in Second Language}

Attention is relevant in understanding the foreign teaching assistant language problem only if can be shown that attention makes a difference. Two cases need to be established: (a) students are inherently more likely to attend to structural features of language (e.g., syntax, morphology, and phonology) than to discourse features, and (b) those students that attend more to academic discourse are more likely to learn its particularities. Let us consider the first case.

I maintain that there are predispositional differences for attention among language facts. In other words, there are certain facets of language that learners are more likely to attend to than others. This claim is not controversial in the sense that it is frequently or vehemently denied. Rather, it suffers from benign neglect. The issue is very rarely raised and thematized.

I suggest that learners have an automatic tendency to attend to basic facts of syntax, pronunciation, and semantics in a language they are learning. This is a part of the LAD (language acquisition device) developed for accounting for the acquisition by children of their native language. Children notice (though not necessarily consciously) the basic facts of syntax, pronunciation, and semantics of 
their native language and acquire them. While it is incontrovertible that all competent adult native speakers achieve a basic mastery over the syntax, phonology, and semantics of their language, the same may not be the case when we consider the ability to construct types of discourse. Not everyone achieves basic competence in writing, especially in particular genres, such as writing business letters. Although all of us may have some ability to recognize and judge stories, some of us are much better than others at telling them. Notice that competence here requires knowledge of the genre rules and the ability to apply them skillfully in practice (as discussed above). Likewise, there are differences in how good native speakers are at talking and responding like teachers. Children are naturally compelled to acquire grammar, but are not so compelled to become good storytellers, liars, or lovers. Children are compelled by law to attend schools, but they are neither compelled to attend to teacher discourse closely, nor to learn to master it themselves.

\section{Reasons for Lack of Attention to Relevant Factors}

The case hinges on the claim that foreign students will naturally not attend to relevant factors in the discourse of the classroom and academic offices. There are several good grounds which can be provided for this claim. Some of these are based on the typical behavior of foreign graduate students. Some are based on the nature of academic discourse itself.

\section{General Lack of Reliance on Lectures}

Before we can consider attention to particular phenomena in classroom discourse, it is necessary to consider the degree to which foreign graduate students attend to the ambient speech of the classroom. The reason for this is that if they tend to ignore much of what goes on in the classroom, then there is little likelihood that they will attend to particular phenomena.

Several foreign graduate students report that they gain very little from the lectures they attend; however, the students do not necessarily receive less information than is required for university success - especially if they are students of one of the sciences. Within several scientific fields, the content of lectures does not diverge significantly from the content of textbooks and other auxiliary materials. Moreover, in several sciences much of the content of the lectures can be reconstructed from what is written on the board. In situations like these a student could potentially succeed even if all of the words uttered in the classroom were ignored. A student in such a situation might not feel it is worth it to expend the energy required to learn to follow what is said in the classroom. Such a student, moreover, may feel that, if she were a teacher, it would not be important for her to produce standard classroom discourse.

\section{Generative Theory of Learning}

Even if a student does pay careful attention to what the professor says, this is not a sufficient guarantee that she will notice a particular facet of the classroom 
discourse. Students come to class to learn about the subject matter, not to concentrate on the discourse per se. According to the generative theory of learning discussed above, different students may learn from the same input in different ways. They may well attend to different facets of the classroom language. Some may fail to pick up on definite clues as to what is going on in the language of their professors. This is another way in which little or no attention may be paid to relevant facets of classroom discourse.

\section{Montage/Polyphony}

Another reason why students may not attend to all aspects of the spoken discourse of a teacher is that it is simply not necessary to attend to the entire discourse for comprehension. Rather, the interpretation can be gleaned from just a part of what the teacher does. A text of any length and complexity is not composed of a single thread which a comprehender must completely analyze in order to understand the text, but rather is an assemblage of many threads. There is simply no need for the comprehender to analyze all of the threads. Her job is simpler and all she needs to do is glean information from one or more of the threads. This has been discussed with regard to comprehending academic and scholarly texts by Ard (1985; forthcoming). This notion of interwoven threads has been described as polyphony with regard to novels by Bakhtin (1984) and as montage with regard to cinema by Eisenstein (1949).

This same concept of montage/polyphony is also applicable to academic settings, a point made by Ulmer (1985). Several threads are woven together in a classroom. The teacher produces several signals; through body posture, body gestures, facial expressions, tone of voice, writing on the board, the actual words spoken, etc. There are also several threads in the spoken words. The content is important, but there is also commentary on the content, including various signalling words and phrases and asides. Furthermore, there are other threads which have been woven outside the classroom, especially those in the textbooks or auxiliary materials.

Montage/polyphony creates different demands on the teacher and the student. The student can pick and choose, paying attention to only as much of the information in different threads to yield an understanding. The teacher, on the other hand, has to weave all the threads together. She cannot skip the threads that she doesn't use at all in understanding classroom discourse herself, because these threads may be important for some of the students.

\section{Types of Communicative Action}

In thinking about communication in the classroom, what most readily comes to mind is the communication of objective facts, regarding the contents of the subject matter. This is certainly a relevant part of classroom communication, but according to Habermas's (1984) model of communicative action it is only one part of communication. In addition to the communication of objective facts, he considers two other types of communication. There is the communication of information about the social world, especially of adherence to or rejection of 
social norms. There is also communication of information about subjective worlds, of presentations of self in Goffman's terminology (Goffman, 1981). These other two types of communicative actions, which he called normativelyregulated and dramaturgical action, are also relevant in the classroom. In fact, these other types may be even more important in determining teacher success, as foreign students become foreign teaching assistants.

The issue of what communication behaviors are most highly valued in teachers has been investigated in a series of articles in the journal Communications Education. Most of these studies have been empirically based on surveys of student responses. A common chord that resonates in these studies is that teacher success is generally not highly correlated with the amount of content taught. Higher correlations obtain with factors that correspond to normativelyregulated and dramaturgical action. For example, Andersen, Norton, and Nussbaum (1981) found that "good" teachers in American colleges were perceived as more dramatic, open, relaxed, impression leaving, and friendly. These variables are most closely relatable to the notions of presentation of self.

While dramaturgical and normatively regulated actions are apparently those most crucial for determining the success of a teacher, this does not mean that these are the types of communicative actions most closely attended to by foreign teaching assistants in the classes they are taking or have taken recently. From self-reports, they seem to be most interested in attending to the objective content, which is what they will be tested on while a student. Indeed, there is anecdotal evidence that foreign students in a classroom are less likely to notice anything unusual when the discourse of a teacher or student violates a social norm or expresses a self-image in an unusual way. Thus, foreign students are in a difficult situation. What is most important for them to attend to in their role as students is not the same as what is important for them to attend to in their (potential future) role of a teaching assistant.

In summary of these remarks, there is little inherent motivation for foreign students to attend to aspects of classroom discourse that are most relevant for conveying normatively regulated and dramaturgical action. Yet these types of communicative actions are more likely to be important in determining their success as teachers than is their ability to convey objective facts about the subject matter.

\section{Differences in Genre}

In general, foreign graduate students, especially those who did not receive their undergraduate instruction in English, are usually more competent in comprehending textbooks (written) than classroom (spoken) discourse. Since they have achieved some degree of competence in the written genre of textbooks, they may not attend as closely to the different states of classroom discourse.

There is evidence that being competent in spoken and written genres does not automatically transfer. Kaplan and Palhinha (1982) discusses the general nature of these relationships in adult second language learners. Similarly, children in their first language may tend to use phenomena more appropriate for the spoken mode in their writing (Hidi \& Hildyard, 1983). 
The direction of transfer (when it occurs) seems to be from a genre in which one has a high degree of competence to another in which one has a lower degree of competence. Thus, the tendency of foreign graduate students to sound too much like a "talking textbook" when they are addressing students orally is very reasonable. This would tend to happen automatically, unless they attend to the differences in the genres.

\section{Evidence for the Current Analysis}

The above discussion has been designed to show the reasonability of the hypothesis that attentional factors play a major role in accounting for the foreign teaching assistant language problem. In this section, more direct evidence in support of the hypothesis will be given.

One type of evidence comes from self-reports of foreign teaching assistants. As we have seen, several report that they pay very little attention to the lectures given in classes they attend. When asked what they think is most important about teaching in the classroom, few mention factors that could be related to normatively-regulated or dramaturgical action. They emphasize the importance of content. Some have indicated that an important factor is the amount of content that is covered in some unit time interval. When asked specifically about roles, some respond that their primary role is to be an authoritative expert, a role not greatly appreciated in a foreign teaching assistant by the typical American undergraduate. Moreover, Bailey (1984) compiled a typology of teaching assistants, in which she found meaningful differences between American and foreign teaching assistants. It is interesting to note that most of the categories she described (namely, active unintelligible TAs, mechanical problem solvers, knowledgeable helpers/casual friends, entertaining allies, and inspiring cheerleaders) are better described in terms of dramaturgical action than normatively regulated or objective communicative action.

Another source of support for the hypothesis comes from a study by Chaudron and Richards (1986) of listening comprehension by foreign students in American universities. They tested the comprehension of two versions of a lecture, one with and one without what they called micro-markers. These micro-markers included such words and phrases as: "okay", "for the moment", "on the other hand", "naturally", "as you know", and "all right." These micro-markers are not so much markers of content as they are signals about how the content is to be interpreted, for example, Is the information new? and Does it follow from what was just said? etc. Chaudron and Richards found that the presence or absence of micro-markers had no effect on the lecture comprehension of these foreign students.

One interpretation of these results is that the foreign students failed to attend to these micro-markers. The importance of this for our discussion is that these micro-markers are examples of language forms that good teaching assistants would be expected to use in the classroom. This experiment indicates that foreign students generally do not pay much attention to these language structures in their role as students. 


\section{Discussion}

The purpose of this paper is to foster increased dialogue between research on the language problems of foreign teaching assistants and on second language acquisition. The potential benefits from second language acquisition theory are obvious - better instructional programs. The benefits in the reverse direction are to test the acquisition theory and to improve it if necessary. A general theory of acquisition must be able to come to grips with the particularities of the acquisition of the specific uses for language required by foreign teaching assistants.

I have argued that second language acquisition theory is not presently able to account for the facts of development by foreign teaching assistants. It cannot predict which students will succeed and which will fail at the acquisition task. Three special properties of the acquisition task were highlighted: (a) a special purpose of language use is what is to be acquired, (b) students must require competence in the generic norms (of teacher discourse) and in their use in interaction rather than the more static and formal knowledge witnessed in syntax, phonology, and morphology, and (c) students must learn an asymmetric type of discourse, that is, they must learn to use a kind of language that they are not allowed to practice in everyday interactions, since they, in their role as students, do not talk to teachers the same way teachers talk to them. A further topic for research is how similar the acquisition of other special purposes of language use is to this type of acquisition.

I have maintained that the essential variable necessary to account for the difference between success and failure is attention to the discourse. This has direct pedagogical implications. Overt instructional moves can be made to increase the attention of potential foreign teaching assistants to the properties of college discourse. This move would be in line with suggestions made for instruction before in different contexts. Pedagogical approaches based on Soviet research on activity and orientation emphasizes the role of directing students' awareness. This is also an important component of "inner game" approaches to instruction (Green \& Gallwey, 1986).

In the instructional setting, it is also possible to recreate facets of the setting deemed helpful for acquisition (e.g., negotiated input and comprehended output) which are naturally missing in the normal situation in which foreign graduate students find themselves. Simulated activities can enable these students to initiate and respond to typical teacher and student talk under the supervision of and with feedback from teachers.

(Received March 1987)

\section{REFERENCES}

Andersen, J., Norton, R., and Nussbaum, J. (1981). Three investigations exploring relationships between perceived teacher communication behaviors and student learning. Communications Education. 30, 377-392.

Ard, J. (1985). Vantage points for the analysis of scientific discourse. ESP Journal, 4, 3-19. 
Ard, J. (forthcoming). From sign to text in mathematical discourse. In Yishai Tobin (Ed.) From Sign to Text. Amsterdam: John Benjamins.

Bailey, K. (1984). A typology of teaching assistants. In K. Bailey, F. Pialorski, and J. Zukowski/Faust (Eds.). Foreign Teaching Assistants in U.S. Universities. (pp. 110-125). Washington, DC: National Association for Foreign Student Affairs.

Bailey, K., Pialorski, F., and Zukowski/Faust, J. (Eds.). (1984). Foreign Teaching Assistants in U.S. Universities. Washington, DC: National Association for Foreign Student Affairs.

Bakhtin, M. (1984). Problems of Dostoevsky's Poetics. Minneapolis: University of Minnesota Press.

Bakhtin, M. (1986), Speech Genres and Other Late Essays. Austin: University of Texas Press.

Chaudron, C., and Richards, J., (1986). The effect of discourse markers on the comprehension of lectures. Applied Linguistics. 7, 113-127.

Eisenstein, S. (1949). Film Form. New York: Harcourt, Brace, and Company. Gal'perin, P. Ja. (1959). Razvitie issledovanij po formirovanniju umstvennyx dejstvij. In Psixologičeskaja nauka v SSSR. $t$. I. Moscow: Izd. APN RSFSR.

Gass, S. (forthcoming). Integrating research areas: a framework for second language studies. Applied Linguistics, 8(3).

Goffman, E. (1981). Forms of Talk. Philadelphia: University of Pennsylvania Press.

Green, B., and Gallwey, T. (1986). The Inner Game of Music. New York: Anchor Press.

Habermas, J. (1984). The Theory of Communicative Action (Vol. 1) Reason and the Rationalization of Society. (translated by Thomas McCarthy). Boston: Beacon Press.

Hakuta, K. (1976). A case study of a Japanese child learning English as a second language. Language Leaning, 26, 321-352.

Hidi, S and Hildyard, A. (1983). The comparison of oral and written productions in two discourse types. Discourse Processes, 6, 91-105.

Jonassen, D. (1985). Generative learning vs. mathemagenic control of text processing. In D. Jonassen (Ed.) The Technology of Text. (Volume 2). Principles for Structuring. Designing, and Displaying Text. Englewood Cliff, N]: Educational Technology Publications. 9-45.

Kaplan, J., and Palhinha, E. (1982). Non-native speakers of English and their composition abilities: a review and analysis. In William Frawley (Ed.) Linguistics and Literacy (pp. 425-457). New York: Plenum Press.

Krashen, S. (1980). The input hypothesis. In J. Alatis (Ed.) Current Issues in Bilingual Education. (pp. 168 - 180). Washington, DC: Georgetown University Press.

Larsen-Freeman, D. (1983). The importance of input in second language acquisition. In R. Andersen (Ed.) Pidginizaton and Creolization as Language Acquisition. Rowley, MA: Newbury House.

Leontiev, A. (1981). Psychology and the Language Learning Process. Oxford: Pergamon Institute of English.

Nagle, S. and Sanders, S. (1986). Comprehension theory and second language pedagogy, TESOL Quarterly, 20, 9-26. 
Rothkopf, E. Z. (1970). The concept of mathemagenic activities. Review of Educational Research, 40, 325-336.

Rounds, P. L. (1987). Multifunctional Personal pronoun use in an educational setting. English for Specific Purposes, 6, 13-29.

Swain, M. (1985). Communicative competence: some roles of comprehensible input and comprehensible output in its development. In S. Gass and C. Madden (Eds.) Input in Second Language Acquisition. (pp. 235-253). Rowley, MA: Newbury House.

Ulmer, G. (1985). Applied Gram matology. Baltimore: Johns Hopkins University Press.

Varonis E. and Gass, S. (1985). Non-native/non-native conversations: a model for negotiation of meaning. Applied Linguistics, 6, 71-90.

Wittrock, M. C. (1974a). Learning as a generative process. Educational Psychologist, 11, 87-95.

Wittrock, M. C. (1974b). A generative model of mathematics learning. Journal of Research in Mathematics Education, 5, 181-197.

Wittrock, M. C. (1978). The cognitive movement in instruction. Educational Psychologist, 13, 15-29.

Josh Ard is an Assistant Professor at the English Language Institute and the Linguistics Program of the University of Michigan. His interests include textual theory, scientific discourse, communication problems of foreign TAs, and second language acquisition. 